\title{
Varieties of National Experience: Resistance and Accommodation in Contemporary Slovenian Identity"
}

\author{
ALE S DEBELJAK
}

Our troublesome fin de siècle seems to be a period marked by many "ends." Francis Fukuyama promotes "the end of history," Jean Baudrillard advances the thesis of "the end of the social," Daniel Bell talks about "the end of ideology," Michel Foucault analyses "the end of the subject," while many left-wing writers pontificate on "the end of the nation" (Kumar 149-200). If anything, however, the end of the 2oth century is experiencing, I suggest, the end of the idea of the nation-state, which is gradually falling prey to the global circuit of anonymous transnational capital. While the nation-state, the modern form of which grew out of the 19th century European emancipatory movements, had been in a position to more or less successfully control economic tendencies throughout its territory up until the Second World War, such control is today next to impossible. In the light of the efforts of mega-corporations to establish a global market beyond any specific borders - linguistic, political, ethnic or religious - with their tacit spelling out of the rules for the operations of individual national governments, the "national" source of capital is not only unidentifiable but also utterly irrelevant. It seems that culture in particular represents the last remaining sphere that may be able to preserve some of the features of a specific national experience. I will draw on the case of Slovenia to demonstrate, pars pro toto, how it is possible to reconcile a particular national tradition with the universal mechanisms of globalization. In this regard, Slovenian examples should be seen as an illustration of larger processes that may be applicable, with a certain degree of heuristic caution, to the situation of other numerically small Eastern and Central European nations.

A nation with a fully developed cultural identity obviously has no problem in facing outside challenges and influences. Indeed, facing up to different mentalities and forms of behavior is the only attitude Slovenians should adopt in order to avoid succumbing to the alluring sirens of self-sufficiency, provincial xenophobia, various forms of exclusivism and the national withering that results. The "other" becomes incomprehensible, robbed of his/her humanity and con- 
sequently an enemy only when members of a given national polity are unsure of their own negotiated identity. In the case of Slovenia, for example, there should be little doubt about the existence of a specific national cultural identity. The accomplishments of leading writers, artists, and other creative minds provide the Slovenian nation with a strong sense of cultural identity regardless of the fact that they are but a handful of the total Slovenian population. However, let me be adamant about the following: these creative impulses, such as they were historically and are today, should emphatically not be understood as exclusively Slovenian in an (admittedly often used) ethnic sense of the word. There exists a vibrant, albeit small, current of creative and intellectual voices that have participated, and continue to actively exercise their participation, in Slovenian public life, yet are not necessarily embedded in an ethnic Slovenian tradition.

A few examples should suffice. Emyl Korytko, a Polish émigré in $19^{\text {th }}$ century Ljubljana, gathered Slovenian folk songs and ethnographic material long before this task was taken up by ethnic Slovenian scholars themselves. Lily Novy, a prominent early $2 \mathrm{O}^{\text {th }}$ century poetess, was one of the pillars of Slovenian literary modernism even though her ethnic background and mother tongue were German. Maria Nablocka, a famous theater actress between the two world wars, was of "white Russian" extraction. Branko Gavella, an ethnically Croatian theater director, was instrumental in expanding the expressive forms of modern Slovenian performing arts, while Czech film director František Čap with his hugely popular post-World War II films almost single-handedly established a coherent foundation for the modern Slovenian film industry. When it comes to contemporaries, Josip Osti, a prolific and much-celebrated writer, who is Bosnian in his cultural and ethnic background, Jette Ostan, a Danish theater actress, and Svava Bernhardsdottir, an Islandic violinist for the Slovenian Philharmonic are futher cases in point. While these random examples serve more to illustrate the argument than to empirically validate my theoretical insistence on a separation of ethnic and civic identity in the public life of a Slovenian nationstate, they nevertheless emphasize that, against all historical odds and against very real dangers of post-independence Slovenian chauvinism, one is invited to see the admittedly small in numbers yet artistically and, no less relevant, politically productive participation of individuals who chose their civic identity without giving up their attachment to the ethnic communities from which they emerged. The latter aspect, that is, one's civic identity and concomitant "constitutional patriotism" (Habermas) is certainly far from being fully established as the norm in contemporary Slovenian public life. Yet I refer to these individuals to better outline the possibilities for multiple identities that a modern, secular, universalist polity is made of and the chief guarantor of which is a democratic nation-state. This aspect needs to be stressed because in an era of both voluntary and forced migrations (particularly in the wake of the Yugoslav wars since 
1991), the issue of civic identity will ever more urgently haunt the willfully myopic Slovenian political elite and those that manipulate symbols and ideas in public discourse. It is thus of paramount importance that the separation of ethnic and civic identities is kept in mind as one contemplates the current convulsions of nation-states, all the more so in light of the fact that the multiplicity of identities was, up until the mid-197os, allowed to enjoy a considerable degree of public currency in a former federal state of Yugoslavia. In the latter, it was not only possible but broadly accepted that an individual could have at least a dual identity, both as a e.g. ethnic Croat, Serb or Macedonian and as a member of a larger political polity that was Yugoslavia. This lesson seems almost entirely lost on people who have opted for the definition of their nation-states in terms of exclusively ethnic, rather than inclusively civic identity. For Slovenian citizens in particular, this lesson should be recuperated and reformulated in a post-independence Slovenian nation-state insofar as the recent history of Slovenian struggles to maintain ethnic identity against a perceived threat of having been swallowed up in a larger ethnic frame clearly demonstrates the continuing relevance of sensitivity to the rights of ethnic minorities and multicultural competence. If anything, the refusal to grant weight to "the discourse of numbers," i.e. the size of ethnic communities as a criterion for participation in a politically defined civic nation-state, should be a necessary building block in the development of Slovenian civic identity since it was the very argument of small numerical size that was so often in the past used to deny the Slovenian right to exist as a separate people.

I hasten to add that a small number of people, two million, does not necessarily make a nation small. Moreover, it would not be impossible to argue that the "smallness" of a nation may be measured first and foremost in regard to how much the citizens believe in their nation's creative potential and the richness of their cultural tradition.

The argument of small numerical size as evidence in support of the claim about the inevitable, if gradual absorption of the Slovenian nation in the "larger context" is often used today in Ljubljana, the capital of the nation, as well as in Brussels, the capital of the European Union. It is, alas, far from new. A quick glance at Slovenian history reveals a long tradition of this erroneous, albeit politically potent "numbers game." To offer but one example, one can recall the $19^{\text {th }}$ century Ilyrian tradition of literary writers like Stanko Vraz and Ljudevit Gaj, who called for the unification of the Slovenian and Croatian languages on the basis of alleged "linguistic pragmatism." After the First World War, this argument, advanced by the central communist authorities of the federal state, manifested itself in the ideological straight-jacket of "integral Yugoslavism" (Wachtel 78 et passim). Today, the argument is often promoted by those numerous and loud members of the political elite who do not understand politics in the an- 
cient Greek sense, that is, as a discussion of res publica, "public affairs." Instead, they view it as nothing else but a sheer technology of power. As such, they mistakenly believe that Slovenians can somehow be European in a direct, unmediated, and "natural" sense, without first being who Slovenians really are: the citizens of the Slovenian nation-state. In other words, the fact that Slovenians are Europeans only insofar as they are citizens of the Slovenian nation-state goes almost entirely lost among the folds of the "numbers game."

I am convinced, though, that the issue should be reversed. It was precisely the numerical limitation of Slovenians as a people that forced the key players in the Slovenian national culture to interact with foreign strategies of creativity and thinking, critically recuperating them according to their own will and principles. After all, the small population, coupled with a productive, if troublesome, geographic location at the crossroads of the Romanic, Hungarian, Germanic and Balkan cultural traditions from which it draws its manifold constitutive elements, has always presented our ancestors with the impossibility of an ideal of bucolic "sameness." The concept of self-absorbed and uncontaminated Slovenian culture where a national ego in Arcadia would be quietly nurtured is, of course, but an illusion.

Slovenian creative minds have traditionally been engaged in a dialogue with the gospel of Western civilization, drawing on the linguistic self-confidence of Protestantism, the Italian Renaissance, the Central European baroque, French rationalism, German Romanticism and Expressionism, historicist Viennese architecture, English rock 'n' roll, American pop-art and French nouvelle vague films, not to mention the allure of the Hollywood screen and the intricacies of Balkan folk blues.

The idea that art and culture, if understood only as a formal ornament to public life, can provide neither national freedom nor unfettered flights of imagination, appeared very early in Slovenian history. The sheer decorative, nonsubstantial character of works of art and the cultural tradition at large would, of course, end in nothing other than a gradual decay. The leading Slovenian literary critic in the period between the world wars, Josip Vidmar, captured the importance of local interaction with the tendencies of the wider world in his seminal essay "The Cultural Problems of Slovenian Identity" (1932). He vividly explained that a small nation is "like a very uneven peninsula - the ocean keeps splashing against its many shores and the fresh wind infinitely blows over its entire surface" (Vidmar 73).

This commitment to the "winds" of Central European sentiment and the "ocean" of the Western civilizing experience has personally helped me in two ways. Both as a literary artist using universal codes of expression to present what I believe is an individual vision, and as a Slovenian with a particular collective experience in my background, I gradually came to see that it would be 
impossible to divorce myself from the treasure of my national cultural references, knowledge of which allowed me to appreciate and integrate the experience of other cultural traditions. A truly cosmopolitan personality can only be one, I surmise, who comfortably traverses the various cultural meridians of the planet without giving up the reflection of his/her national roots. Such genuine cosmopolitanism was, for example, exercised in the creative opuses and personal biographies of James Joyce, Pablo Picasso, Rainer Maria Rilke, Samuel Beckett and Paul Celan, whose works display a remarkable degree of multicultural competence. Their chosen language of expression was enhanced by nuances and semantic possibilities precisely because it rested on a close proximity and cross-fertilization with other languages and cultural traditions.

Moreover, it can be argued that their respective civic identities were fundamentally arbitrary insofar as they were chosen by free subjects. Rational identity of citizenship as a matter of choice differs sharply from a "natural" ethnic identity to the extent that it is based on a republican respect for differences and active public expression rather than succumbing to the oft-invoked, though essentially passive, camouflage of "tolerance." Such cosmopolitanism links without unifying. Politically speaking, it contributes to a transformation of "natural," "inherited," "genuine" identities into a civic identity based on a common body of laws that is freely accepted by free and therefore equal individuals. This acceptance of rule of law can only be performed in modern nation-states (Raulet 51).

In post-independence Slovenia, there are two types of provincialism that combat this kind of civic and cosmopolitan habitus. The first one was given birth to by the conservative nationalistic formula of an autarkic, rabidly exclusivist and often violent "navel gazing," i.e. the mentality that cannot, would not, and is unable to learn anything from others, much less accept "others" (those that are ethnically not Slovenian) into public life. The second kind of provincialism is represented by the bona fide liberal "internationalists" whose main characteristic might be seen in the fact that they despise each and every aspect of the national cultural identity because they fear being lumped together with the exclusivist nationalist zealots. As a result, this position drives "internationalist" liberals toward an uncritical approval of each and every idea that comes from "the West." Such minds offer a servile, ingratiating "bless you!" when this or that fashionable cultural guru sneezes in Paris, London or New York.

Both kinds of opponents to the admittedly uneasy glocal dialectics [see $\mathrm{Da}$ kovic in this volume] are active in contemporary Slovenia. This constellation is, alas, not all that different from other post-communist countries. The velvet revolutions in 1989 indeed produced a semblance of the renaissance of the national ideas in Eastern and Central Europe, encouraging debates on the validity of the national cultural experience and teasing people with the cheap utopian 
promise of miraculously resolved conflicts in newly independent countries. Almost a decade after the annus mirabilis, however, it has become rather clear that only a very few original approaches to the relation between the national and global aspect of collective identity emerged from the ruins of the communist ancien regime. Intellectuals from Central and Eastern Europe have, with the largely thoughtless transplantation of assorted Western stereotypes and conceptual forms, almost unanimously accepted the role of "poor relatives" that only compete with each other in efforts to impress their rich cousins in Europe, that is, Western Europe.

However, what kind of Europe are we really talking about? I, for one, remain convinced that the discussion must primarily concentrate on the following difference between two aspects of "the European idea." On the one hand, one must entertain the project of integrating the diverse European societies, an enterprise based exclusively on economic and technological standards. As such, this is a goal that is as interesting as it is crucial. On the other hand, one must take measure of Europe as a common, if elusive spiritual and mental realm. What is the price of the first aspect taking over the second? Modern European epiphany does not reveal itself solely in the noble tradition of Roman law, Greek philosophy, Renaissance art and Romantic poetry, and of the politically crucial Enlightenment legacy of universal human and civil rights. The contemporary idea of Europe is also increasingly being advanced in popular right-wing politics of "fascism with a smile" and "fortress Europe." This highly conservative gatekeeping is cast as a tool to bolster what is perceived as a "natural" ethnic community to which one must either be born or one does not belong. Tertium non datur.

No less relevant is the fact that, after the dismantling of the Berlin Wall and after German reunification, Western Europe cannot, despite the ever-growing homogenization of global markets and rising levels of economic integration within EU-member states, obscure its moral failure and political sterility. Indeed, the internal disintegration of its political and moral backbone was in a particularly excruciating way laid bare in the third Balkan war in 1991-1995, where European diplomacy for the most part struggled to deny the basic right of self-defense to Bosnian and Croatian victims. This situation is painfully reminiscent of the 1930s, a period in which Europe was blindly proud of its arrogant authority of "the sick... secret diplomacy that trades with territories of small nations, calming down the rebellious looks with the League of Nations, run by the traders and oppressors themselves," as the Slovenian avant-garde poet Srečko Kosovel wrote in 1925 in his lucid public lecture "Disintegration of Society and Decay of Art" (Kosovel 40). Kosovel was, needless to say, describing the situation in his own time. His prophetic insight, however, poetically intimates the situation today. 
More to the point: thrilled by the political proximity to Western Europe and full of resentment at the present Serbian political madness of national socialism, those who shape the Slovenian public discourse all too often grow oblivious to the fact that, in the contemporary world, the philosophy of postmodern domination no longer requires machine guns to express itself. The primary strategy today appears to be the use of forms of the seemingly harmless "ethnically neutral" economy, transnational capital, uniform cultural patterns and a gradual mass media unification of each and every particular mentality and idiosyncratic experience.

If Slovenia is to survive as a full-fledged civic and modern secular nationstate in these times of unavoidable economic integration and vapid rhetoric about a "united Europe," then one must keep in mind not only the capacities of economic productivity, but also those of national operas and theaters. Successful businessmen should thrive equally well supporting a variety of national and regional TV and radio stations; political know-how should be thought about in the same breath as the accomplishments of the diverse creative and intellectual impulses in the country. While it is certainly not easy for such impulses to extend their reach beyond national borders, the importance of cultural creativity nonetheless lies in serving as a constant reminder that, after the declaration of independence in 1991, the Slovenian dilemma was no longer spontaneously expressed in terms of the defeatist traditional formula, advanced by the 19th century local writer, Fran Levstik: "We can either be Russian or Prussian." Today, Slovenians can finally be themselves.

Having said all that, I make no bones about the claim. I do realize that there is no point in pretending to ignore relevant historical and socio-political processes that have led to the contemporary condition. In other words, from the village champions (Yugoslavia), Slovenians have become the Olympic losers (Western Europe). Instead of colonization with the accompanying politics of Italifying, Germanicizing and Serbifying under the guise of an integral "Yugoslavism," all of which were fought against not in the least because the enemy was possible to define, we are now facing anonymous multinational capital. Its formidable forces are discussed by Slavoj Zizek in "Multiculturalism Or The Cultural Logic Of Multinational Capitalism” (Zizek 102-03). Here, this internationally recognized philosopher bitterly argues that multinational capital no longer calls for the use of unmediated violence, since particular cultures are much more effectively destroyed by the global market itself.

How to respond to this challenge? I have no original answer. As a poet, though, I simply think that inspiration may still be drawn from the rich heritage of Slovenian cultural innovation and experiment, if not directly from literary works of art. Cold comfort, I admit. It is, alas, most likely the only comfort we have. A political program that would ignore the manifold cultural components 
of national identity in Slovenian efforts to join the European Union would soon find itself in a position where it would be reduced to managing a perhaps better paid, yet sorrowfully hollowed-out labor force, whose main attraction for foreign investors would be its comparatively low hourly wage.

A responsible attitude towards the national tradition is essential to the extent that culture is not a gift from our ancestors. Instead, Slovenians have borrowed it from their own grandchildren, if such a sentimental claim is permissible. Today's situation is less than promising. In Central and Eastern Europe, one is dealing with ethnic fundamentalism which prioritizes the ideology of Blutund-Boden, on the one hand, and an upsurge of a-national liberalism, inadvertently embedded in the social-Darwinist logic of the market on the other.

Benjamin Barber described in his meticulously researched Jihad vs. McWorld these intertwined processes as a mixture of hatred and privileging of the tribal form, on the one hand, and the all-embracing maximization of profit on the other. Specific movements founded on the basis of ethnic, religious or cultural obsessions with a prescribed and, as a rule, exclusivist way of communication, which Barber ominously calls Jihad, as well as McWorld movements (aspirations for uniformity and homogenization promoted by global corporations and, more often than not, trans-national bodies such as the IMF and World Bank), share many similarities despite their mutual hostility. The underlying idea of both is a dismissal of democracy. Jihad uses the bloody policy of ethnic exclusivism, while McWorld prefers the bloodless economy of profit. The result of the former is voluntary blindness which persecutes traitors of the tribal "cause," while the latter induces a consumerist rigor mortis where we all do nothing but "entertain ourselves to death."

Under neither the Jihad's canopy nor the McWorld umbrella, however, is there place for a citizen. This is Barber's theoretically most fruitful insight. While Jihad replaces the citizen by a paranoid warrior, McWorld cheerfully cultivates an ignorant consumer. If the ancient Greek truth si non est civis, non est homo is today as valid as it should be, then accepting either Jihad or McWorld will mean a premeditated catastrophe. Without the comprehensive experience of citizenship, there is no democracy.

The emphasis on democracy within this context is essential if one is to realize that the democratic order provides conditions for the emergence of a public sphere with its capability to produce conditions for emergence and sustenance of various personal practices and freely chosen cultural styles as well as multiple identities. In this regard, it is crucial to improve the existing institutions of the political state and, if necessary, develop new mechanisms that foster and nurture the possibilities of the kind of personal identification which allows one to choose one's identities, thus enjoying "constitutional patriotism" regardless of ethnic origins, race, and tradition. Insofar as civic identification with the in- 
stitutions of the political state based on the rule of law and equal participation in public life is the only buffer against the insipid forces of ethnic nationalism which exclude different (other, minority, foreign) forms of cultural expressions on the one hand, and against the hollow idea of world-citizens wherein it remains profoundly unclear as to which democratically elected bodies, if any, actually do represent citizens and make them act in accordance with their rights and responsibilities on the other, the defense of the civic nation-state appears to be of utmost importance. In other words, civic responsibilities, cultural and political rights, both collective and individual, and articulations of one's personal preferences should be defended in a democratic state. In this respect, ethnic identity is but one of the elements for citizen identity, which is based on the separation of national (in terms of a state) and ethnic (in terms of received cultural background) markers. Such a modern state arises from the development of a secular, universalist and democratic polity in which citizens as equals before the law may enjoy the right, though not necessarily the obligation, to organize their life according to their preferred cultural, religious and political stocks of meaning.

This is only possible under the condition that the public sphere is not subsumed either under the mantle of state institutions, thus siphoning off the creative and critical potential of a variety of impulses, programs, and lifestyles that are articulated outside of governmental bodies, nor left to the mercy of economically reductivist and often aggressive corporate interventions into the individual and collective life-world.

Such a public sphere depends on the existence of civil society which, in turn, forms itself through the tension vis-à-vis the political institutions of the nationstate. This tension is a corner stone of a modern democratic society. From this vantage point, the importance of the civic nation-state is unavoidable since it provides the minimum regulation of conditions for the functioning of the multifaceted social life. Zygmunt Bauman, possibly the most lucid theorist of postmodernity in the English-speaking world, in his 1995 book Life in Fragments argues: "The greater... the share of nation-state sovereignty ceded to the allEuropean agencies, the smaller... the chance that the nation-state-based identities will be successfully defended" (249). Should one choose to dismiss the idea of the democratic nation-state, one, thus, in the final analysis, ushers in the proliferation of local and ethnic communities, and concomitantly tolerates the destructive crusade of "fast music, fast food and fast computers" of the global capitalist machine.

Allowing both processes to grow unhindered would in my opinion prove disastrous. The worlds of Jihad and McWorld are by definition incapable of respecting that unity of symbolic, cultural and social experience that builds a multifaceted history of national existence and the collective mentalities that in- 
form it. Both are primarily reflected in the mother's tongue. The latter is not only a mechanical tool of communication. Instead, it must be first and foremost understood as a peculiar worldview. For this writer, a poet by vocation, this aspect is of fundamental relevance in discussing affairs of culture, its pitfalls and advantages.

The fateful intimacy of language and national identity was in Slovenian history best perceived by poets, starting with a founding father of modern letters, Romantic poet France Prešeren. His rejection of German, the language he brought to the highest aesthetic levels, did not imply a simple pragmatic exchange of the means of expression (a financially more powerful area, larger public, bigger market, etc.). Prešeren's commitment to his mother tongue was an embodiment of an existential and political decision, serving as his article of faith that seems to be today gaining a renewed importance. If mother tongue presents a particular worldview, it is possible to argue that it also represents a specific comprehensive perspective that cannot be sufficiently expressed in any other language (Debeljak).

Consider the following anecdote. After a lecture, one of my students once came up to me and ruefully stated that he was really not sure what made him a Slovenian. He surfs the Internet, watches MTV and Hollywood "slash and burn" movies, shops at Benetton, and listens to the regretfully now defunct Viennese international radio station, Blue Danube Radio, while the rural idyll of Slovenian "hayracks" and the rituals of peasant festivities are, understandably and legitimately, lost to him. I am sure that he is not alone in facing this central dilemma. I often wonder about it myself. But when, in the course of our discussion, I switched to English only to prove a point, my student suddenly realized how English, despite being the lingua franca of the modern world and the language of international mass culture, radically narrowed his verbal register and flattened out his imaginative horizon.

It is thus the specific perspective of the mother tongue that integrates many of the cultural, geographic, symbolic and social aspects of national experience. The refuge of our mother tongue is thus the place where every single thing has a name. No wonder. Language, after all, transcends our individuality since it is older and greater than time which is, in turn, older and greater than space, as Joseph Brodsky illuminatingly says in his 1986 essay "To Please A Shadow." Make no mistake: I, too, find the nationalistic logic which ignores all that is foreign and different most repulsive. But that does not mean that I have to automatically subscribe to another extreme which would make me reject the national cultural experience tout court.

Another personal example might better illustrate this point. I happened to have spent many years in the United States. I have my second alma mater there, my publisher, my friends, my editorial affiliations and professional network. In- 
deed, it would perhaps not be too presumptuous to claim that I figuratively live on a bridge between Slovenia and America. In my home in Ljubljana, my wife and I speak American English to each other for she, herself an American, does not yet feel comfortable in her adopted language.

Despite varieties of such "Americanization" of my self, however, I cannot and would not follow the many Slovenian politicians who support economic reductionism and their business counterparts, who blissfully declare that a disrespect of the mother tongue, five hundred words in Basic English and fluency in the rhetoric of cable TV spontaneously puts them on the best path to the promised land of (Western) Europe. I have no desire whatsoever to adopt this formulaic attitude. I cannot support it because I know that a human being cannot live on bread alone. However, this does not necessarily mean that I support the privileges of starvation, either.

If it is true that life without a spiritual sphere in which the existential experience of an individual and of a collective as an "imagined community" (Benedict Anderson) can be fully expressed is but a dull vegetative life, then the economic success of Slovenia in the age of its newly gained independence must be accompanied by a cultural narrative about the symbolic and the material value of language, ethical values, the fateful burden of history and the mythic tradition. This story makes us see our lives against the broader background of the national condition, making us a critical link in the great chain of being that is not going to end with us; it will help us preserve our national culture and language in the current era of European integration that, openly or not, considers smaller nations an unnecessary inconvenience.

Many sceptics would, of course, contest the need to preserve national culture. These voices argue that the concern with res publica should be exclusively a matter for professional politicians. I cannot but think otherwise. I am convinced that the preservation of the cultural conscience in a broader environment of a civil society is essential in a democratic nation-state not only because it is too important to be left to the political elite alone. Now that Slovenians have come to the end of the Yugoslav via dolorosa, understanding the importance of national culture and the many different traditions from which it draws, as emphasized earlier, may prevent the citizens of the Slovenian nation-state from turning into "Viennese lackeys," as the Serbian popular press is wont to call Slovenians. This crass metaphor is, of course, farfetched but it nonetheless forcefully dramatizes the present Slovenian uncritical longing towards the "European Paradise Lost."

If one attempts to resist the current temptation summed up by the perverted Cartesian slogan "I shop therefore I am," then one may still find inspiration - with doubts though not without hope, in a dedicated, though not glorifying way - in the constantly changing and publicly negotiated meaning of the 
cultural tradition. Through these very negotiations and struggles to maintain the multi-layered makeup of the cultural frame, one may perhaps figure out where one stands while attempting to decode the signals of the modern precatastrophic world in which not only individuals but entire nations are being destroyed. Under the pressure of the ideology of "cold peace," entire nations are condemned to disappearance, as we have been all too painfully reminded by the Bosnian tragedy.

To assume a firm stand against both the provincial mindset of ethnic exclusivism as well as that of corporate homogenization, one is invited to look back to the history of Slovenian literature. There, at least to me, the grace of that special light is revealed, in the glow of which our lives are enriched by that narrative which is "just to the complexity and multiple meanings of history and is able to open up a broad realm of human creativity that with the elegance of its form reaches a kind of transcendence and appeals to the better aspects of our selves," as the American critic Neil Postman put it in his opening speech at the Frankfurt Book Fair in 1993.

The inspiration that Slovenes use to measure their distance and proximity to the collective mentality is probably best seen in the characters of literary works of art. Their destinies and struggles are still, in my biased opinion as a literary artist, a great source of inspiration even today. These struggles best reveal how the existential dilemma of Slovenians has always been connected with the dilemma of cultural identity. The latter has not been automatically accepted as a given, as it was not accepted either by Germans or by Serbs. In other words, Slovenians have been living under the same roof in a less than equal relationship with the former for eleven long centuries and with the latter for seventy years.

The characters in Slovenian literature had to fight first for their identity, and second, to ensure wider public recognition. The essential archetype of these rites of passage suggests their contemporary usage. Slovenians have not created a nation-state only to freely enjoy the thrills of ex Occidente luxus. The nationstate should be here to help us be, and not to simply have, to paraphrase Erich Fromm's perhaps forgotten, though, I submit, still very powerful distinction.

The emphasis that I have chosen to place on language and comprehensive, that is, multi-layered and never-fixed national cultural experience has, in the limited context of this essay, but a single ambition: to dramatize the dangers inherent in an entirely economic approach to Slovenian identity. That is, the approach which strives to put each and every affair of culture, art and their social existence at the mercy of the invisible hand of the market. If one is not aware of the history of one's national culture, which cannot and should not be measured according to its "marketability" alone, one may very well turn into a member of the tribe of children with no memory and no concerns and thus, by exten- 
sion, no freedom. H. G. Wells describes the consequences of losing one's sense of history in his work The Time Machine, where such a tribe found itself totally unprotected when it faced cannibalistic children from the dark side.

A small nation at the end of the 2oth century is thus presented both with a challenge and a responsibility to show that its citizens are able to turn freedom from an abstract, if noble concept into a meaningful, if messy, social experience.

\section{NOTES}

* A modified version of this paper was presented at the seminar "On Divided Societies: Concepts and Institutions in Comparative Perspective" at the Interuniversity Center, Dubrovnik, in April 2000.

\section{REFERENCES}

Barber, Benjamin. Jihad vs. McWorld. New York: Times Books-Random House, 1995.

Bauman, Zygmunt. Life in Fragments: Essays in Postmodern Morality. Oxford: Blackwell, 1995. Brodsky, Joseph. Less than One: Selected Essays. New York: Farrar, Strauss, Giroux, 1986.

Debeljak, Ales. Individualizem in literarne metafore naroda. Maribor: Obzorja, 1988.

Kosovel, Srečko. "Razpad družbe in propad umetnosti." Zbrana dela III/1 (1997), Ljubljana: Državna založba Slovenije

Kumar, Krishnan. From Post-Industrial to Post-Modern Society. Oxford: Blackwell, 1995.

Raulet, Gerard. "Citizenship, Otherness and Cosmpolitism in Kant" Otherhood and Nation, ed. R. Iveković and N. Pagon. Ljubljana: ISH, 1998.

Vidmar, Josip. Kulturni problem slovenstva (reprint). Ljubljana: Cankarjeva zalo_ba, 1995.

Wachtel, Andrew. Making a Nation, Breaking a Nation: Literature and Cultural Politics in Yugoslavia. Stanford: Stanford University Press, 1998.

Žižek, Slavoj. "Multikulturalizem ali kulturna logika multinacionalnega kapitalizma." RAZPOL 10, Problemi No. 5-6, Vol. 35 (1997). 